\title{
Strcture and Infrared Optical Properties Research on Fe-Doped $\mathrm{CuAlO}_{2}$ Semiconductor
}

\author{
Chuanmao Lv ${ }^{1, a}$, Yi Huang ${ }^{1, b^{*}}$ Miao Feng ${ }^{1, c}$, Mei Long ${ }^{1, d}$ and Chuanwu Zhang ${ }^{1, e}$ \\ ${ }^{1}$ School of Electronic and Information Engineering, Southwest University for Nationalities, \\ Chengdu 610041, China \\ alv403690216@163.com, boliderhy@126.com, c miaofeng-007@163.com,d longm82@163.com, \\ ${ }^{\mathrm{e}}$ zcw@swun.cn
}

Keywords: Fe-Doped $\mathrm{CuAlO}_{2}$, XRD, IR, Solid-phase sintering, Delafossite.

Abstract. Samples of pure phase $\mathrm{CuAlO}_{2}$ and transition metal element Fe doped were synthesized by solid phase sintered method. The phase structure, optical properties and miscellaneous phase formation mechanism were characterized by X-ray diffraction (XRD) and Infrared Spectroscopy (IR) respectively. The results of XRD show that the product was really pure p-type transparent conductive oxide $\mathrm{CuAlO}_{2}$. Samples containing a small amount of $\mathrm{CuO}$ mixed phase may be caused by block reaction environment. IR spectroscopy results show that the transmittance of the sample was declined with the increasing of the iron-doped concentration. Doped samples have more than one absorption peak is the result of mixed substitution.

\section{Introduction}

Transparent conductive oxide (TCO) are widely used in field of photoelectric devices such as solar cells, flat-panel display, electroluminescent devices and special features window coating for its features such as good electrical conductivity, high transmittance of visible light and infrared reflectivity and the stronger microwave attenuation ${ }^{[1-5]}$. But the actual application of TCO mostly is n-type semiconductor and $p$ type content is less. This hinders the research and development of transparent photoelectric device TCO to set up on the basis of the p-n knot semiconductor. So far, the electrical conductivity of p-type $\mathrm{CuAlO}_{2}$ materials is still low contrast with common n TCO and it gives a bigger challenge in research and development of $\mathrm{p}$ type $\mathrm{CuAlO}_{2}{ }^{[6-8]}$.

So far, many researchers used different methods to prepare $\mathrm{CuAlO}_{2}$ polycrystalline materials. Using $\mathrm{Al}_{2} \mathrm{O}_{3}$ and $\mathrm{Cu}_{2} \mathrm{O}$ as raw material, Ishiguro ${ }^{[9]}$ ultimately prepared $\mathrm{CuAlO}_{2}$ polycrystalline at $1200{ }^{\circ} \mathrm{C}$ in air. $\mathrm{GaO}^{[10]}$ obtained $\mathrm{CuAlO}_{2}$ polycrystalline by solid phase reaction of $\mathrm{Cu}_{2} \mathrm{O}$ and $\mathrm{Al}_{2} \mathrm{O}_{3}$ at $1100{ }^{\circ} \mathrm{C}$ in nitrogen atmosphere. Ma Tao ${ }^{[11]}$ prepared low infrared absorption $\mathrm{CuAlO}_{2}$ polycrystalline under 1200 ${ }^{\circ} \mathrm{C}$ by sol gel method. Doped-Fe $\mathrm{CuAlO}_{2}$ were prepared by solid-phase and the infrared spectral characteristics of the sample were studied in the article.

\section{Experimental}

$\mathrm{CuAl}_{1-\mathrm{x}} \mathrm{Fe}_{\mathrm{x}} \mathrm{O}_{2}$ semiconductors were synthesized by solid state reaction. Reactant materials $\mathrm{Cu}_{2} \mathrm{O}$, $\mathrm{Al}_{2} \mathrm{O}_{3}$ and $\mathrm{Fe}_{2} \mathrm{O}_{3}$ were weighed according to standard stoichiometric ratio. Then the reactants were put into the anhydrous ethanol. The mixed solutions were fully milled by using ball mill for $24 \mathrm{~h}$. After that, the samples were put in high temperature furnace for pre-sintering after dried. Sintered powders were ball milled again. All powders were sintered at $1200{ }^{\circ} \mathrm{C}$ for $10 \mathrm{~h}$ after dried. The $\mathrm{CuAl}_{1-\mathrm{x}} \mathrm{Fe}_{\mathrm{x}} \mathrm{O}_{2}$ powders of different doping proportion were obtained after cooled. The phase composition of powders samples were characterized by using DX-2000 X-ray diffraction. To research optical property of powders samples, the Infrared Spectroscopy were carried on the NEXUS670 type infrared spectrometer. 


\section{Results and Discussion}

The result of CuAlO2 powder sintered at $1200{ }^{\circ} \mathrm{Cfor} 10 \mathrm{~h}$ is shown in the Fig. 1. It can be found that the sample is $\mathrm{CuAlO}_{2}$ by the comparison and analysis of XRD patterns of the sample and $\mathrm{CuAlO}_{2}(\mathrm{PDF}$ 35-1401) standard spectrum. It can be seen that the sample has $\mathrm{CuAlO}_{2}$ and $\mathrm{CuO}$ two crystalline phases from the Fig. $1 . \mathrm{CuAlO}_{2}$ is the main phase which the diffraction intensity is stronger and content is more. $\mathrm{CuO}$ is an intermediate product which the diffraction intensity is weak and content is less. The emergence of a small amount of $\mathrm{CuO}$ mixed phase may be the result of the reaction between $\mathrm{Cu}_{2} \mathrm{O}$ and oxygen, or intermediate part decomposed into $\mathrm{Cu}_{2} \mathrm{O}$ at high temperature, and then $\mathrm{Cu}_{2} \mathrm{O}$ combined with residual oxygen in the process of cooling crystallization ${ }^{[12]}$. This is a foundation for the production of $\mathrm{Fe}$ - doped $\mathrm{CuAlO}_{2}$ powders.

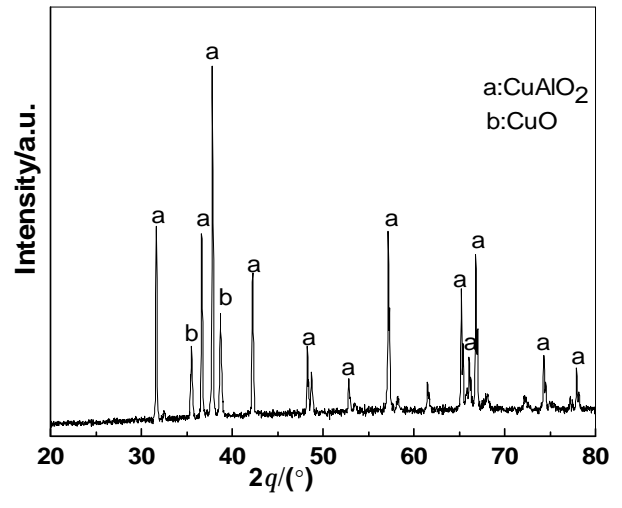

Fig.1. XRD patterns of $\mathrm{CuAlO}_{2}$

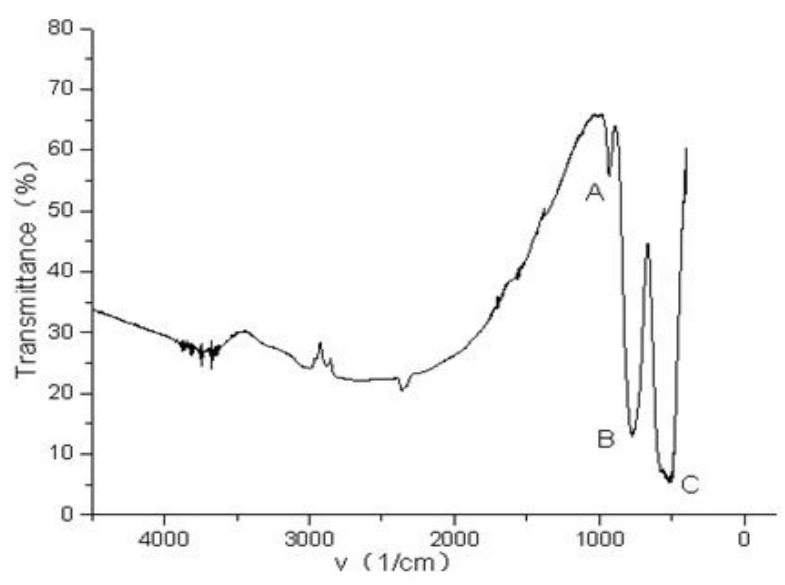

Fig.2. Infrared spectrum of $\mathrm{CuAlO}_{2}$

The infrared spectrum test results of $\mathrm{CuAlO}_{2}$ powder is shown in the Fig.2. There are three relatively strong absorption peaks $\mathrm{A}, \mathrm{B}$ and $\mathrm{C}$ located at the wave number of $933.55 \mathrm{~cm}^{-1}, 711.53$ $\mathrm{cm}^{-1}$ and $513.07 \mathrm{~cm}^{-1}$ place as apparent from Fig.3. The absorption peaks intensity of $\mathrm{B}$ and $\mathrm{C}$ are unusually strong. The absorption peaks are caused by a bond between the vibration of $\mathrm{Al}^{3+}$ and $\mathrm{O}^{2-}$ which can be known that the sample contains the structure of $\mathrm{AlO}_{6}$. The strength value of $\mathrm{A}$ is weaker than those of $\mathrm{B}$ and $\mathrm{C}$. The vibration absorption peak is caused by a bond between $\mathrm{Cu}^{+}$and $\mathrm{Al}^{3+}$, from which can be known a sample that each $\mathrm{O}^{2-}$ ions associated with 4 cation around it $\left(3 \mathrm{Fe}^{3+}\right.$ and $\left.1 \mathrm{Cu}^{+}\right)$constituting a quasi-tetrahedral structure. In addition, the strongest infrared transmittance of sample can reached $65 \%$.

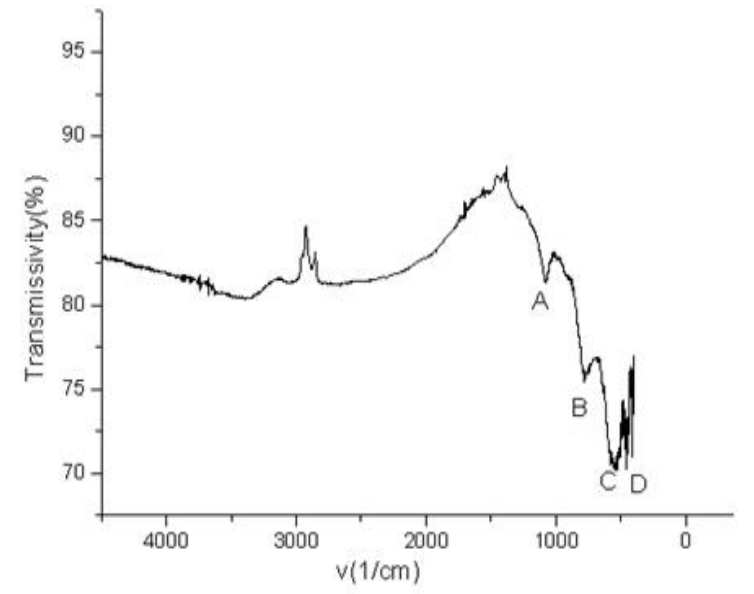

Fig.3. Infrared spectrum of $\mathrm{CuAlO}_{2}(2.5 \% \mathrm{Fe})$

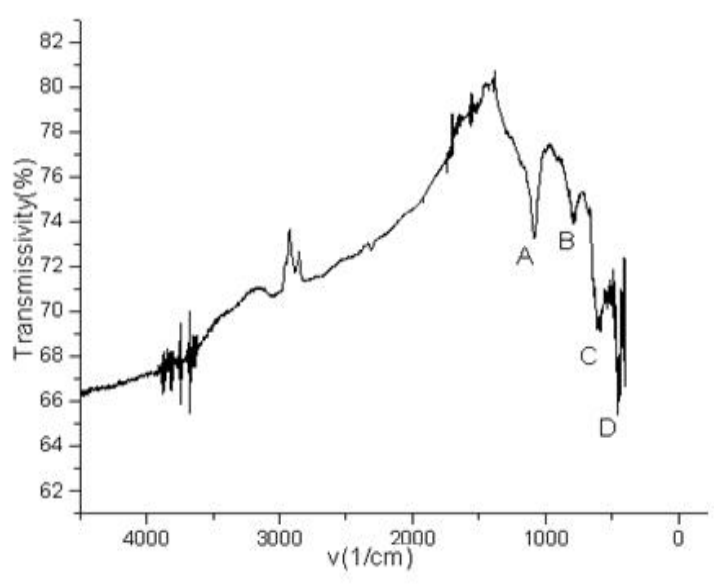

Fig.4. Infrared spectrum of $\mathrm{CuAlO}_{2}(5 \% \mathrm{Fe})$

The measured infrared spectrum is shown in Fig.3 6 where the concentration of the mixed Fe were $2.5 \%, 5 \%, 7.5 \%$ and $10 \%$ respectively. Comparing with the infrared spectrum of pure $\mathrm{CuAlO}_{2}$, the 
wavelength of characteristic peak of mixed iron has a downward trend. The number of absorption peaks is one more than the pure sample. The absorption peak is caused by a bond between the vibration of $\mathrm{Fe}^{3+}$ and $\mathrm{O}^{2-}\left(\mathrm{Fe}^{3+}\right.$ partially substituted $\left.\mathrm{Al}^{3+}\right)$, which a sample that each $\mathrm{O}^{2-}$ ions associated with four cations around it constituting a quasi-tetrahedral structure. The characteristic peak wavelengths of doped samples with concentration increasing are showed different trends. This shows that absorption of $\mathrm{CuAlO}_{2}$ in the infrared region will have been affected by doping. In addition, from the four pair of infrared spectra can be seen that infrared light transmittance of samples has a downward trend with the concentration increasing of Fe. Therefore, the influence of Fe-doped concentration on transmittance is negative.

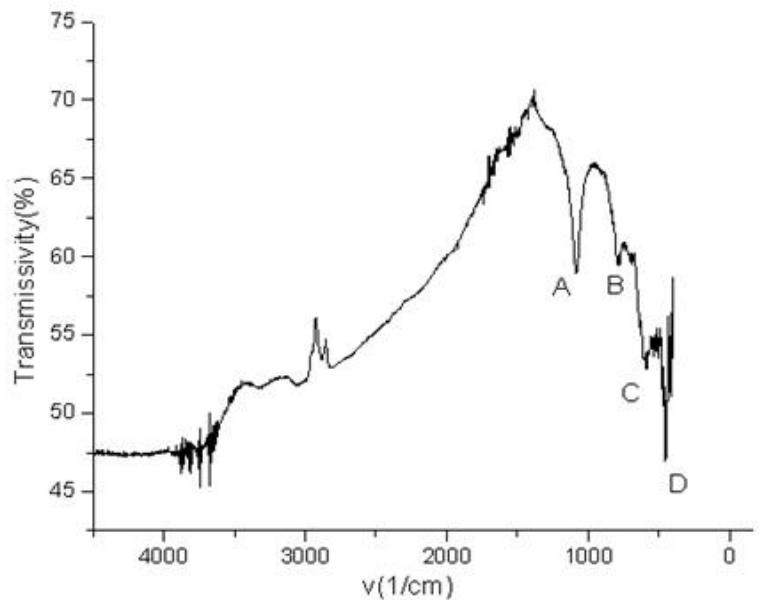

Fig.5. Infrared spectrum of $\mathrm{CuAlO},(7.5 \% \mathrm{Fe})$

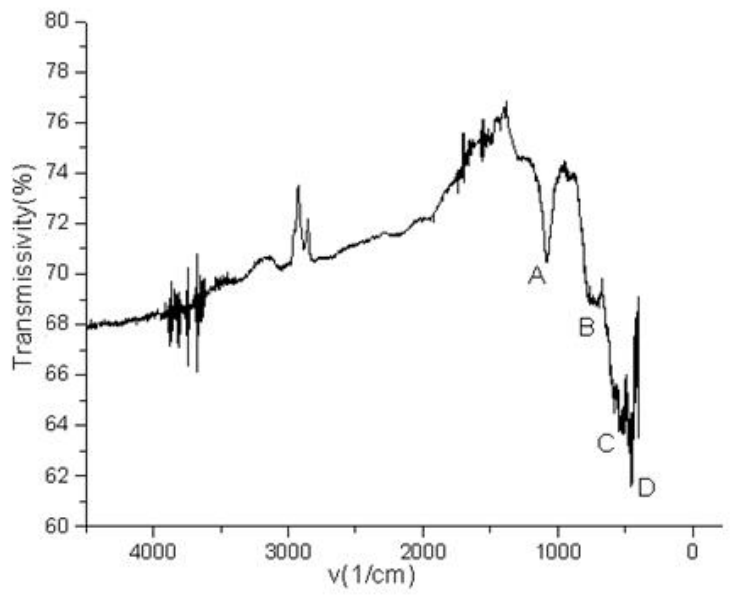

Fig.6. Infrared spectrum of $\mathrm{CuAlO}_{2}(10 \% \mathrm{Fe})$

\section{Conclusions}

Using $\mathrm{Al}_{2} \mathrm{O}_{3}, \mathrm{Cu}_{2} \mathrm{O}$ and $\mathrm{Fe}_{2} \mathrm{O}_{3}$ as reactive material, delafossite structure of high purity $\mathrm{CuAl}_{1-\mathrm{x}} \mathrm{Fe}_{\mathrm{x}} \mathrm{O}_{2}$ polycrystalline material, were prepared by the solid phase. It is shown that the product is really $\mathrm{CuAlO}_{2}$ polycrystalline by XRD test. The emergence of a small amount of $\mathrm{CuO}$ mixed phase may be produced by the reaction of $\mathrm{Cu}_{2} \mathrm{O}$ and oxygen. It is shown that $\mathrm{CuAl}_{1-\mathrm{x}} \mathrm{Fe}_{\mathrm{x}} \mathrm{O}_{2}$ containing $\mathrm{AlO}_{6}$ functional groups and a quasi-tetrahedral structure constituting by $\mathrm{O}^{2-i o n s}$ and it was surrounded four cationic in the sample by IR spectra, which have a major contribution on the optical properties of $\mathrm{CuAl}_{1-\mathrm{x}} \mathrm{Fe}_{\mathrm{x}} \mathrm{O}_{2}$ samples. $\mathrm{CuAlO}_{2}$ has a high transmittance in infrared light, but the transmittance of samples was declined with the doping concentration increasing.

\section{Acknowledgements}

The research work was supported by the Fundamental Research Funds for the Graduate (No.CX2015SZ107), Southwest University for Nationalities.

\section{References}

[1] Craciun, V, Craciun,D, Wang, $X$, Highly conducting indium tin oxide films grown by ultraviolet-assisted pulsed laser deposition at low temperatures. Thin Solid Film, (2004) 256-261.

[2] Tian-hui Zhang, Ling-yu Piao, Su-ling Zhao, New Progress in study of organic solar cell,Materials. Chinese Journal of Organic Chemistry, 31(2011) 260-272.

[3] Fu-rong Zhu, Ke-ran Zhang, Low B L, Morphological and electrical properties of indium tin oxide films prepared at a low processing temperature for flexible organic light-emitting devices.Materials Science and Engineering B, 85(2-3) (2001) 114-117.

[4] Fu-rong Zhu, Ke-ran Zhang, Optimized indium tin oxide contact for organic light emitting diode applications. Thin Solid Film, 363(1-2) (2000) 314-317. 
[5] Huai-ying Ye, Wen Li, Wei-shi Li, Progress in Polymeric electron-donating materials for organic solar cells. Chinese Journal of Organic Chemistry, 32(2) (2012) 266-283.

[6] Craciun,V, Craciun,D, Wang,X, Highly conducting indium tin oxide films grown by ultraviolet-assisted pulsed laser deposition at low temperatures. Thin Solid Film, 453(2004) 256-261.

[7] Kawazoe,H, Yangagi,H, Kazushige U, Transparent p-type Conducting Oxides: Design and Fabrication of P-N Heterojunctions.MRS Bulletin,25(8), pp.28-362,2000.

[8] Kim,D.S, Choi,S.Y, Wet-oxidation effect on P-type transparent conducting $\mathrm{CuAlO}_{2}$ thin film.physica status solidi (a), 202(15) (2005) 167-169.

[9] Ishiguro,T, Kitazawa.A, Mizutani,N, Kato,M, Single-crystal growth and crystal structure refinement of $\mathrm{CuAlO}_{2}$. Journal of Solid State Chemistry, 40(2) (2004) 170-174.

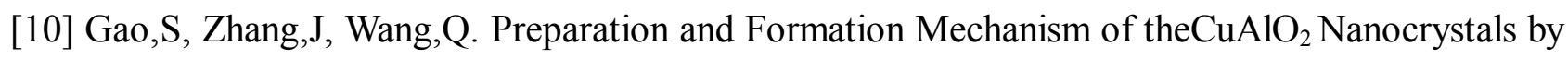
Hydrothermal-Decomposition Method. Journal of Functional Materials, 37(1) (2006) 117-119.

[11] Tao Ma, Yi Huang, Jian Ma, Properties of $\mathrm{CuAlO}_{2}$ Polycrystal Synthesized by Sol-gel Method. Journal of Synthetic Crystals, 41 (2012) 1386-1390.

[12] Guo-bo Dong, Ming Zhang, Wei Lan, Electrical transport properties of $\mathrm{CuxAlO}_{2}$ ceramics.The Chinese Journal of Nonferrous Metals, 9(17) (2007) 1470-1474. 